\title{
IMPACT OF ARTIFICIAL INTELLIGENCE AND DIGITAL ECONOMY ON INDUSTRIAL REVOLUTION 4: EVIDENCE FROM BANGLADESH
}

\author{
Dr. Mohammed Masum Iqbal \\ Professor \& Dean \\ Faculty of Business \& Entrepreneurship \\ Daffodil International University, Dhaka, Bangladesh \\ E-mail: deanfbe@daffodilvarsity.edu.bd \\ (iD) https://orcid.org/0000-0001-9414-0773 \\ K. M. Anwarul Islam \\ Associate Professor \\ Department of Business Administration \\ The Millennium University, Dhaka, Bangladesh \\ E-mail: anwarul@themillenniumuniversity.edu.bd \\ (iD) https://orcid.org/0000-0002-5305-6724 \\ Nurul Mohammad Zayed \\ Assistant Professor \\ Department of Business Administration \\ Daffodil International University, Dhaka, Bangladesh \\ E-mail: zayed.bba@daffodilvarsity.edu.bd \\ (D) https://orcid.org/0000-0001-7519-6552 \\ Tahrima Haque Beg \\ Assistant Professor \\ Department of Management and Finance \\ Sher-e-Bangla Agricultural University, Dhaka, Bangladesh \\ E-mail: sau.finance1@gmail.com

\section{Shahiduzzaman Khan Shahi \\ Independent Researcher \\ Department of Real Estate} \\ Daffodil International University, Dhaka, Bangladesh \\ E-mail: shahi27-334@diu.edu.bd \\ iD https://orcid.org/0000-0003-4669-9104
}

Received: September 23, 2021 Accepted: November 12, 2021 Online Published: December 13, 2021

DOI: 10.46281/amfbr.v6i1.1489

URL: https://doi.org/10.46281/amfbr.v6i1.1489 


\begin{abstract}
This research investigates effects of artificial intelligence and digital economy on the $4^{\text {th }}$ industry revolution from the perspective of Bangladesh. Artificial intelligence affecting the labor market both positively and negatively. Because of artificial intelligence, few existing jobs have been demolished and few new jobs have been emerged as well. Digital economy in Bangladesh is now an emerging issues with the blessings of artificial intelligence. Few employment opportunities will be created in Bangladesh because of emerging digital economy. The objective of this research is to analyze these opportunities and come out with few policy recommendations to implement towards industry revolution 4. Secondary data have been used along with recent relevant literatures to achieve the above stated objective as this is an empirical research. Ideas regarding revised national plan, financial tools, emerging digital economy in Bangladesh are the prominent outcome of this research. The policy recommendations of managing the gap between digital economy and industry revolution 4 regarding artificial intelligence could be helpful to The Government of the Peoples' Republic of Bangladesh to implement policies.
\end{abstract}

Keywords: Artificial Intelligence, Digital Economy, Industry Revolution 4, Bangladesh, Labor Market, Policy.

JEL Classification Codes: L0, D74.

\title{
INTRODUCTION
}

The Fourth Industrial Revolution (FIR) has become a trendy word. Bangladesh is being compelled by globalization to adopt 4.0 Industrial Revolution technologies (FIR).

In the 4.0 industrial revolution, artificial intelligence is starting to deliver on that promise of delivering actual value, which is necessary based on currently available data, processing capabilities, and algorithms. The success of this modern technology in a given country is determined by the country's culture, customs, moral codes, legal, and financial condition.

Both developed and underdeveloped countries will have significant hurdles in dealing with FIR technology. Because of their advanced technologies and competent people resources, rich countries may be at a lower danger than poor countries (Zhaltyrbayeva et al., 2021).

FIR developments can be a basic power in helping Bangladesh in accomplishing its objectives. In any case, the public authority faces a stupendous test in standardizing FIR. To manage the FIR's specialized development, the public authority should embrace legitimate arrangements. Something else, the FIR will be a revile for Bangladesh instead of a gift from heaven. This review will figure the political-monetary circumstance in Bangladesh under the FIR and dissect the progressions and difficulties that the execution of the FIR has achieved.

In 2019, the World Bank anticipated that increased automation would threaten around 57 per cent of jobs in OECD countries, 77 per cent of jobs in China, and 47 per cent of jobs in the United States. To deal with FIR innovations, the government will need to change existing rules and strategies.

With the innovation and implementation of numerous new advances in artificial intelligence, nanotechnology, and the automation process, the volume of work and occupations will have increased. Automation, on the other hand, has some drawbacks. 
The expansion of digital platforms in Bangladesh has been fueled by improvements in internet connectivity as well as an increase in the availability of smartphones. In metropolitan areas, particularly in Dhaka, ride-sharing apps and food deliveries have grown commonplace. Bangladesh has surpassed India as the world's second-largest source of internet labour. As a result, there are several chances to investigate the potential of the digital platform economy to generate employment for a large number of Bangladeshi youngsters.

Many third world countries, such as Bangladesh, are focused on the digital economy: a worldwide market for digital freelancing, as a result of growing digitization.

The computerization of a country's economy cultivates not just assistance industry advancement but then likewise homegrown business creation, taking into account quicker monetary development. Many enormous firms in created nations like the United States, the United Kingdom, and Australia are falling back on IT rethinking from nations like Bangladesh to save expenses and dangers, bringing about a new flood in outsourcing.

\section{LITERATURE REVIEW}

Man-made consciousness, advanced mechanics, computer-generated reality, biotechnology, 3D printing, blockchain and the IoT are uprooting individuals in a few enterprises (Park, 2018). As indicated by a late exploration, by 2030, robotization would have supplanted 800 million incompetent representatives throughout the planet (World Economic Forum, 2020). Many academics have projected that the effective transition of mechanization under the FIR will improve the quality and efficiency of industry products (Ghobakhloo \& Fathi, 2019; Zhong et al., 2017). India, Pakistan, Nepal, and Sri Lanka, all developing countries in South Asia, are moving toward FIR. They are endeavouring to fuse FIR progressions into their nearby ventures to upgrade them (Adhikari, 2020; Rashid, 2020). Bangladesh is anticipated to leave the Least Developed Country (LDC) class by 2024 if its present advancement pace proceeds (Kim, 2018).

The first industrial revolution began in the late 18th century in the United Kingdom, with mechanical manufacture (Frey \& Osborne, 2017). Men controlled the workplace at that point, and females were pushed out of creation occupations (Philbeck \& Davis, 2018). As indicated by Macpherson (1962), this upheaval has brought about quick development underway limit, which has prompted industrialization, the foundation of homegrown and worldwide economies, the significance of majority rule governments, and an increment in the northwestern side of the equator's working class. The second mechanical insurgency was a specialized change that happened between the late nineteenth and mid-twentieth hundred years because of abundant regular assets, solid government strategies, and ample work supply (Frey \& Osborne, 2017; Smil, 2005). Business visionaries and money managers utilized innovation to further develop creation cycles, and time saw a flood in things that were the immediate outcome of science and designing (Hughes, 2004). New advancements (steamships, phones, gas turbines, fake manures, rail lines, electric light, and typewriters, among others) were presented at that point, bringing about mass quick industrialization, quality control, the arrangement of metropolitan media communications developments, accuracy fabricating, and the rise of mass travel dependent on inner ignition (Philbeck \& Davis, 2018). Even though the Third Industrial Revolution was dispatched in 1960, it started vigorously after World War II (Frey \& Osborne, 2017). This wellknown uprising had presented the PC, and the web prompted the vote based administration of data, the value decreases, and quick quality improvement, which was all introduced as another 
period of the industrialist framework; change the monetary design for a conflict-torn world, making calculation simpler for organizations and governments (Philbeck \& Davis, 2018). The FIR or 4.0, which is portrayed by applying new ideas like hereditary variables, computerized reasoning, cordless advancements progress, digital actual structure, cloud administrations, web of things, nanotechnology, biotechnology, and 3-D printing into the world's biggest workplace, is now and again portrayed (Schwab, 2017). To adjust to 4.0, governments ought to energize proficient tutoring in new advances, set up a solid connection between schooling and the work market, and stress STEM (Science, Technology, Engineering, and Mathematics) preparing for youngsters. Besides, FIR has brought about a critical pay difference, with just $8 \%$ of the total populace acquiring half of the world's income and the rest $92 \%$ procuring the other half (Arntz et al., 2016).

India, Indonesia, Brazil, Pakistan, Thailand, Nigeria, and Malaysia are among the created and creating economies that have endeavoured to take on the FIR (Bahrin et al., 2016; Iyer, 2018; Ezenwa et al., 2018; Berawi, 2018). Bangladesh is far from the FIR's offices. In any case, due to the accessibility of specialized imports and new settings, the nation will have no trouble zeroing in on infrastructural innovation and advancement ingestion (Gilchrist, 2016; Walcott, 2017).

Bangladesh has seen a remarkable expansion in internet connectivity in recent years, as well as certain supportive policies for digital entrepreneurs (Fintech BD, 2019). Access to capital, on the other hand, is a big stumbling block for digital startups. Furthermore, to promote digital platforms, it is vital to make online transactions as simple as possible (Fintech BD, 2019). Online technologies connect those who need it with people who can supply it (Deloitte, 2018). The majority of customers see advantages in terms of convenience, choice, and openness. Additionally, online platforms allow new providers to enter the market, increasing competition. Users are more willing to locate cheaper products using a comparison platform in this manner, which may also allow the customer to access more knowledge so that they are fully educated about the product, service, or content they want (Oxera, 2015). Businesses can use digital platforms to get help with fundraising, recruiting, marketing, and e-commerce. According to analysis, digital platform companies lower regional barriers, lower marketing costs, and increase the market size (Oxera, 2015).

According to estimates, over 39 million individuals in Bangladesh use Facebook (Statista.com, 2020). As the internet becomes more widely available, many entrepreneurs in Bangladesh are turning to digital channels to expand their businesses. While the proportion of persons who do not have access to credit cards, digital money and cash-on-delivery have become widely accepted methods of payment (BoostDot, 2020).

\section{OBJECTIVES}

The major objective of this paper is to discover the Impact of Artificial Intelligence and the Digital Economy on Industry Revolution 4 in the context of Bangladesh. The specific objectives are to discover the current view of the World Digital Economy for the next few decades based on Artificial Intelligence which is going to play a tremendous role in the Industrial Revolution 4.0. The consequences from the world will create an impact on developing countries like Bangladesh. Finding the prospect of the scenario of Bangladesh is one of the major goals of this paper. This paper identifies the challenges and recommendations for Bangladesh. 


\section{METHODOLOGY}

This article is based on subjective investigation and is qualitative. The evolution looked into the effects of Artificial Intelligence as well as the Digital Economy on the Fourth Industrial Revolution in Bangladesh. The majority of the citations used to achieve this goal were optional. Secondary data and information were gathered from a variety of online sources, including Scholastic Diaries and Manuscripts of various types, College Diaries, and other online sources, among others. The article critically assessed the current global situation and examined Bangladesh's prospects. As a result, a statistical test known as the Volatility test was used in this investigation. In any case, the secondary sources of data were cautiously validated before being included in this analysis. To assess the current condition, various graphs have been used.

\section{RESULTS \& DISCUSSION}

Revenues from AI for enterprise solutions are expected to expand from $\$ 1.62$ billion in 2018 to $\$ 31.2$ billion in 2025 , representing a 52.59 per cent compound annual growth rate (CAGR). Recognition software and tagging, patient data handling, global positioning systems ( GPS, predictive maintenance, the use of methodologies and machine intelligence to predict and thwart potential threats, smart recruitment, and HR systems are just a few of the many enterprise application use instances predicted to fuel AI's massive development.

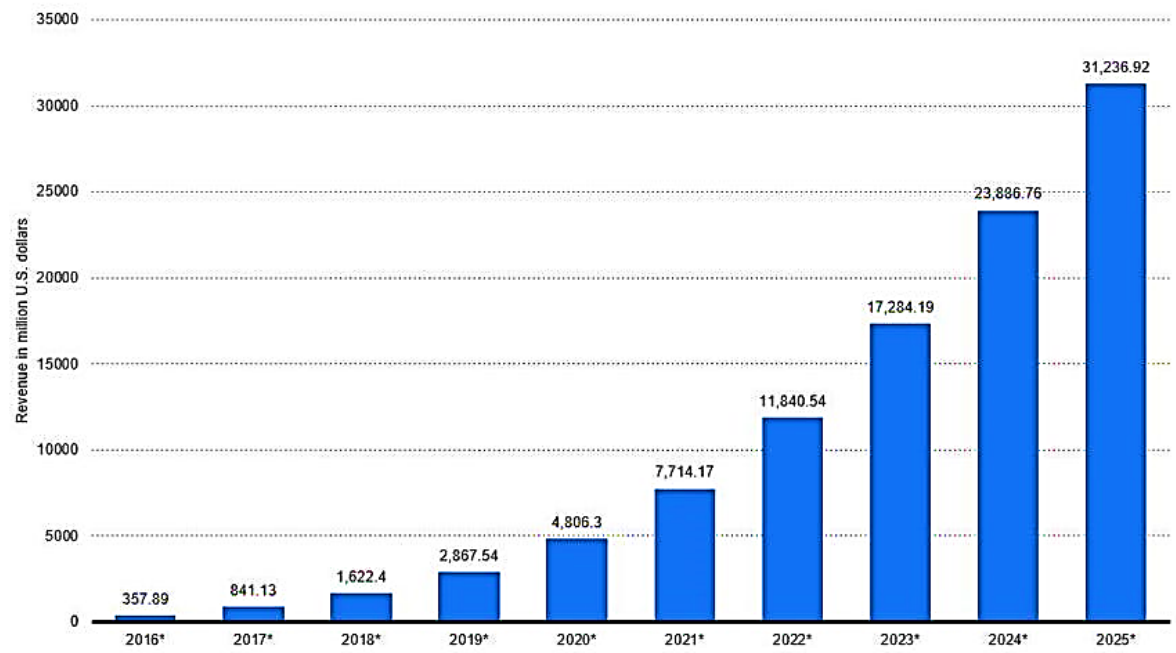

Figure 1. Enterprise Artificial Intelligence Market Revenue Worldwide 2016-2025 (in million U.S. Dollars)

Source: Statista

84 per cent of businesses feel that investing in AI will help them get a competitive edge. Seventy-five per cent say AI will create new enterprises while also giving competitors new methods to enter their markets. Sixty-three per cent feel that they need to save costs will necessitate the employment of AI. 


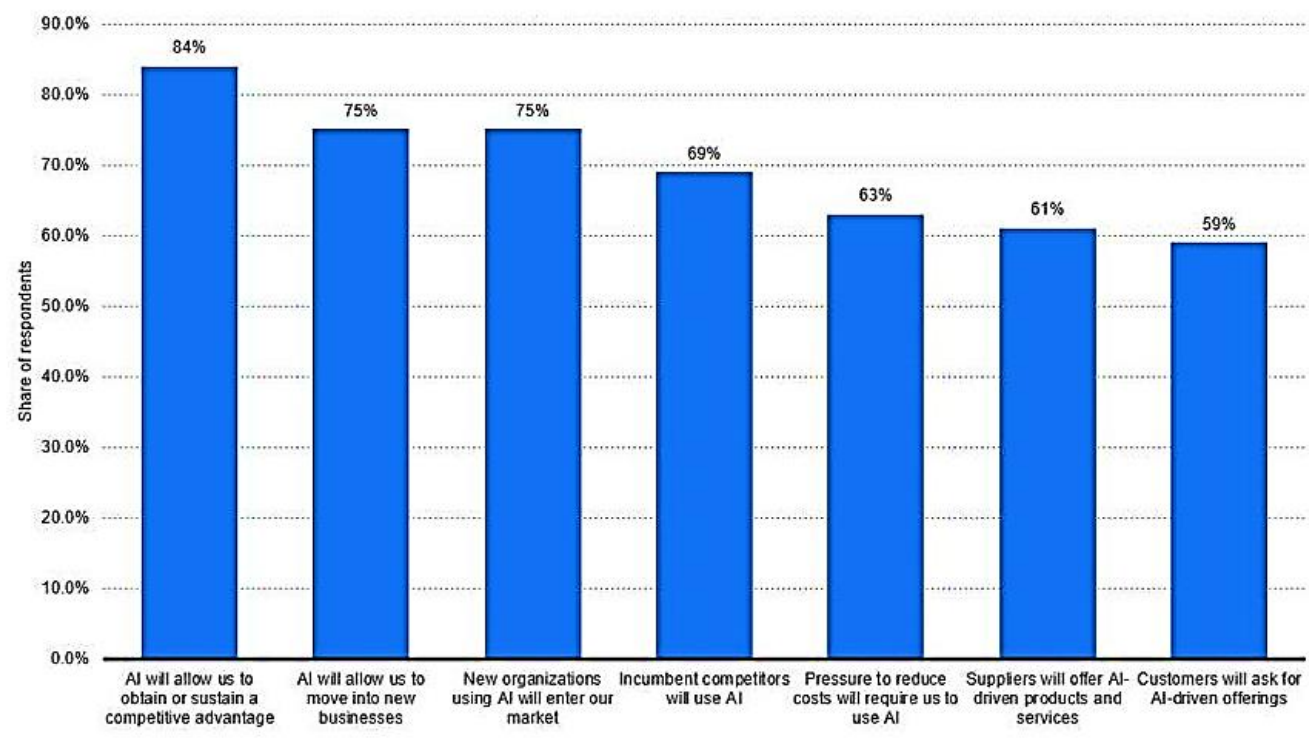

Figure 2. Reasons for Adopting AI Worldwide (as of 2017)

Source: Statista

AI is being used or considered by 87 per cent of existing AI adopters for sales forecasting and boosting e-mail marketing. Sixty-one per cent of respondents stated they were using or intending to use AI for sales forecasting. The graph below compares the adoption rates of existing AI adopters to the overall response rate.

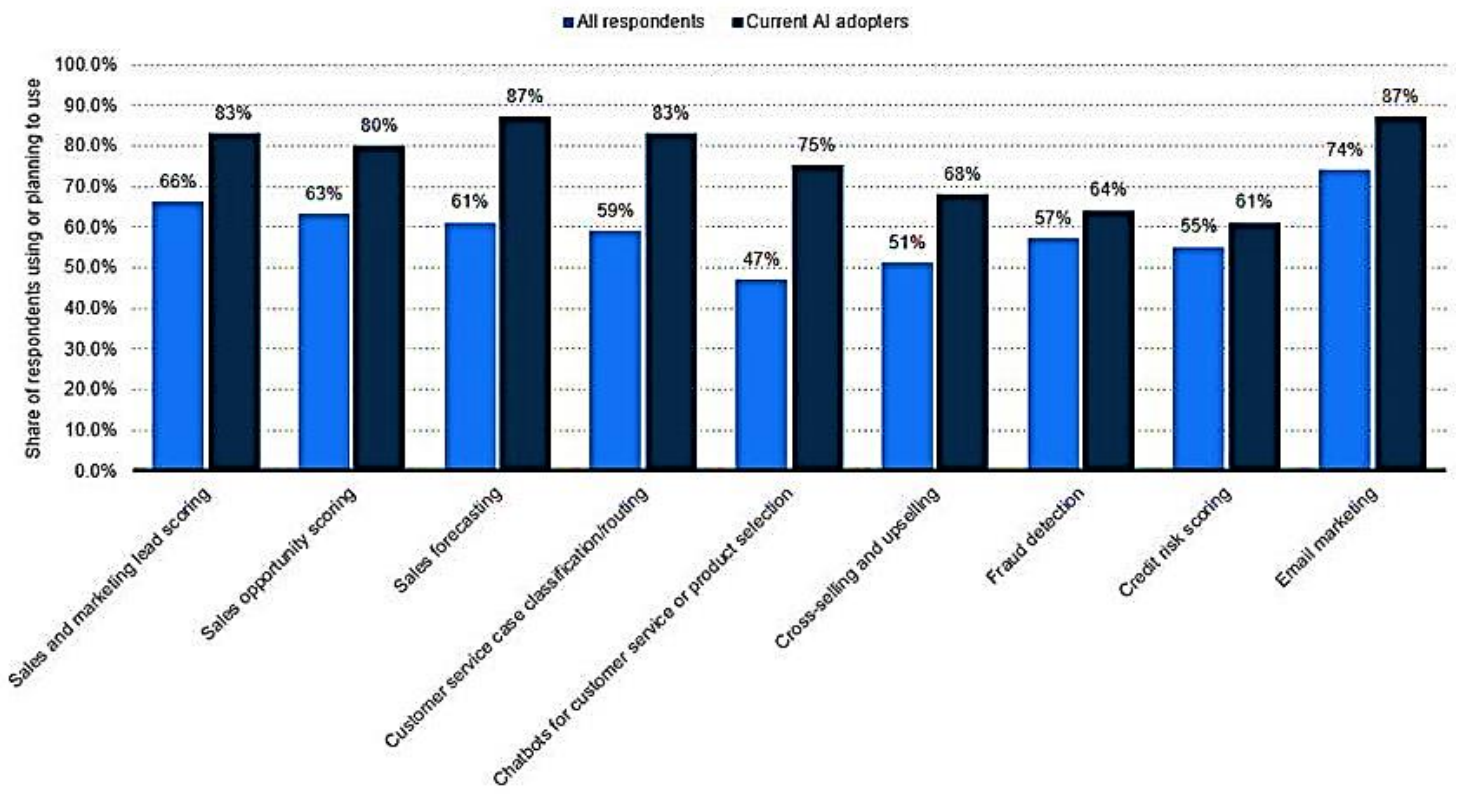

Figure 3. AI Use Case Adoption Worldwide (as of 2017)

Source: Statista 
There are numerous infrastructure issues in Bangladesh, including weak communication and transportation facilities, insufficient broadband internet connectivity, and the regular occurrence of floods and other natural catastrophes, all of which are posing challenges to the automation of the country.

This also makes it difficult for the country to profit from Industry 4.0. Another fact is that Bangladesh has a lot of cheap labour. Because Bangladesh is indeed a developing country, a large percentage of the population is uneducated.

That is why these folks can be found at a low price. As a result, industry owners have no plans to abandon this low-cost labour and investing in infrastructure structures and machinery to adopt Industry 4.0.

Infrastructure that is poor or non-existent is likewise a major impediment. Industry 4.0 necessitates more adaptable buildings with cutting-edge technology. However, practically all factories in Bangladesh are built on a low-cost basis. Another element to consider is the expense of implementing new technologies.

Even though the components of Industry 4.0 are incredibly efficient and valuable for all industries, the initial cost is a major worry. Another crucial fact is that industry owners and associates are unwilling to help.

Many of them believe that everything should remain as it is. In this scenario, government assistance and action would be extremely beneficial. If the government deems it necessary to follow Industry 4.0 rules, each industry will be required to do so.

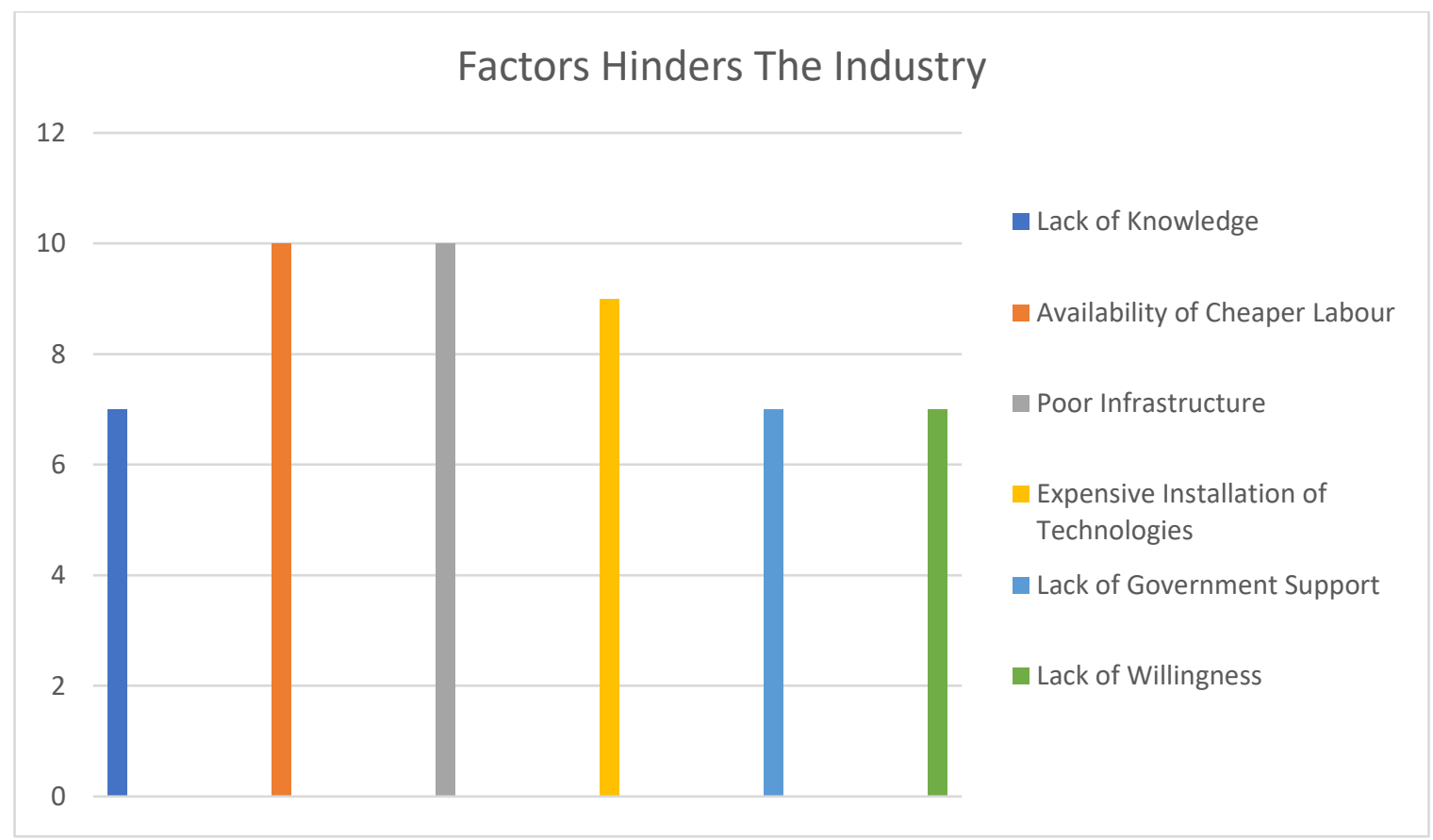

Figure 4. Factors Hinders the Industry

Source: Author's Compilation

Several obstacles are preventing the country from reaping the full benefits of the Digital Platform Economy. This included, among other things, inaccessibility to computers and the 
internet, insufficient worker skills, difficulty in receiving money from overseas, and financial uncertainties, all of which pose a threat to the sector's long-term viability.

Several policy recommendations are suggested to address these difficulties, including equipping individuals with market-relevant skills, researching new financial tools, and developing a 5-year national digital platform economy growth plan. Developing a based practice for the use of information provided by digital platforms, modifying consumer protections to include digital platforms, going to attract capital inflow in digital platforms in Bangladesh, bringing workers and consumers in the digital platform under the tax net, and so on. Increasing digital awareness among the general public, offering tax breaks for new companies entering the digital platform economy, and using economic incentives to encourage brick-and-mortar businesses to move digital.

Bangladesh's increasing digitalization, which includes simple internet connectivity in urban areas and governmental and non-government programs to promote freelancing, has aided this mode of work's recent expansion.

As a consequence, according to the Oxford Internet Institute, Bangladesh has already surpassed India as the second-largest source of online labour (OII). As per the ICT Division of Bangladesh, out of 650,000 authorized freelancers in the country, about 500,000 active freelancing work every month, producing \$100 million annually.

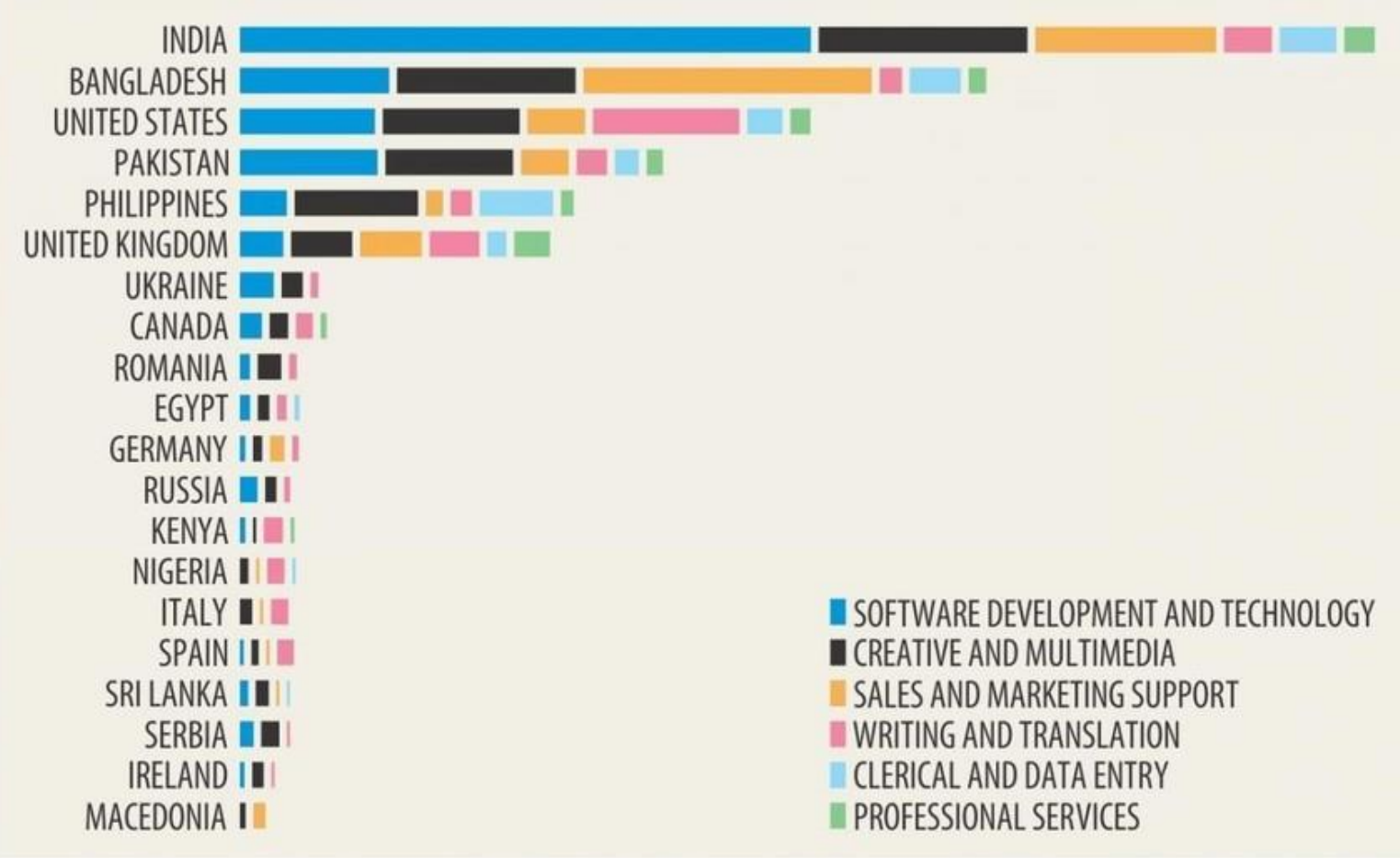

Figure 5. Outsourcing World Rank Source: The Online Labour Index, by Country

India is the leading provider of online labour, accounting for over $24 \%$ of all global freelancers, followed by Bangladesh (16\%) and the United States (12\%). (12 per cent). Different 
countries concentrate on different aspects of freelancing. For example, Indian freelancers monopolize technology and software development, while Bangladesh is the leading provider of advertising \& distribution support services.

According to ADB assessment, Bangladesh would achieve a 7.5 per cent rise in the GDP in the fiscal year 2020-21, the second-highest amongst south-east Asian countries. When most industries, whether large or small, were fighting for survival in 2020, the situation for the ICT industry was radically different. The ICT industry has long been thought to have the potential to disrupt and reshape Bangladesh's economy.

Software development, on the other hand, falls under the IT services umbrella. It is classified as engineering services in the IT services category and is highly sought after by international companies wishing to outsource this aspect of their operations to another country. Platform and software development, testing, specialist software design, and more are all possibilities in this category. This industry is the driving force behind global digital growth, and world-class knowledge in this subject is always in demand. Bangladeshi enterprises have been exporting these services for some time, and freelancers from all around Bangladesh have recently joined them, sourcing work from online platforms such as Upwork and Freelancer on their own. The interconnected and multidimensional character of software development, on the other hand, necessitates the support of multi-talented teams that can only be found in corporations.

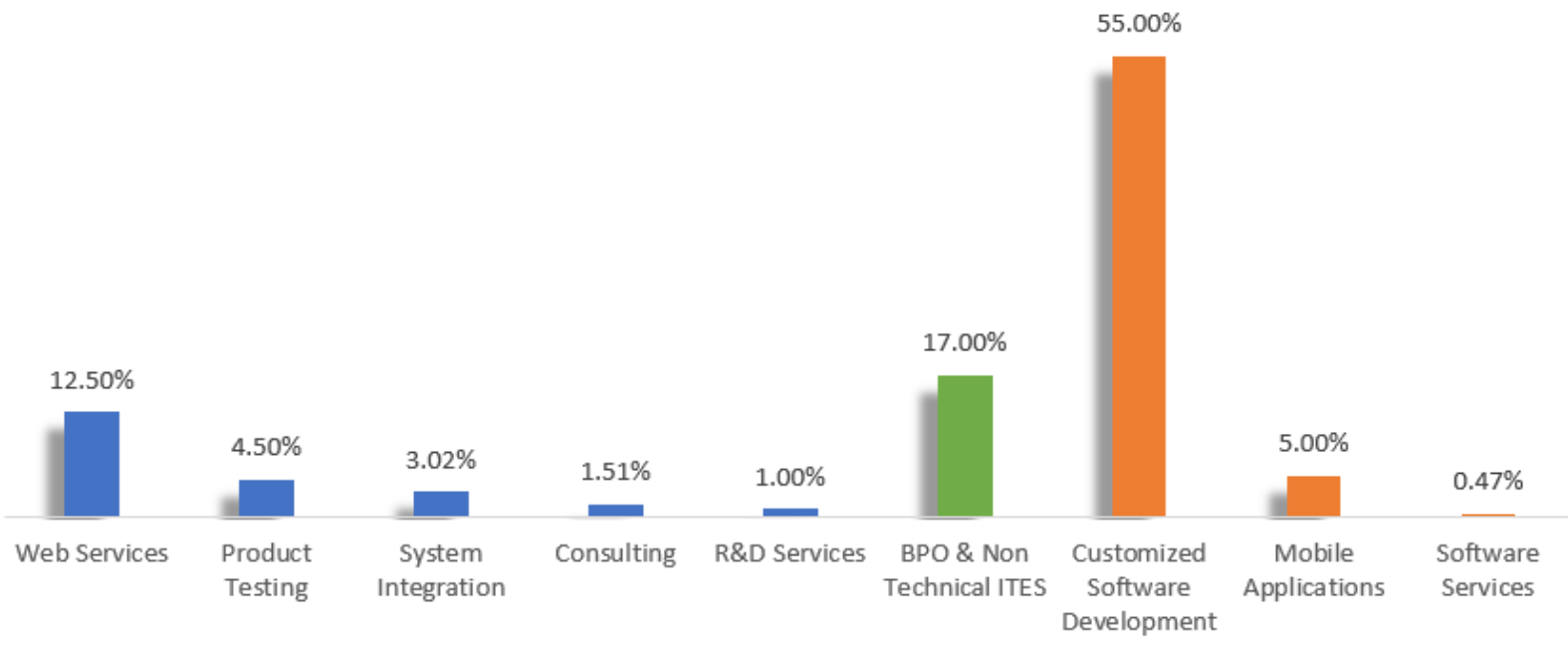

Figure 6. Share in Total ICT Sector (Bangladesh)

Source: Statista

\section{Blessings of COVID-19 on Advancing towards Artificial Intelligence}

E-learning, distance classes, telemedicine, and online activities have all witnessed a huge increase in demand as a result of the pandemic. Bangladeshis have become increasingly accustomed to online purchasing as a result of the lockdown. Year-round, individuals continued to buy more expensive things such as mobile phones, laptop computers, televisions, freezers, and other technological gadgets than they had previously. As for the outcome, there was over Tk 30,000 crore in e-commerce business during the pandemic, with over 2,000 e-commerce business stores across the country. One area that will grow in importance in the coming years is 
e-learning. Although schools, colleges, and institutions remain closed, the administration has made an optimistic effort to maintain education through various platforms and even Sangsad TV.

Another area that has seen great growth in telemedicine. People in Bangladesh could never have imagined consulting with doctors via virtual platforms. People from remote areas are now receiving treatment from Dhaka-based doctors. Telemedicine, e-commerce, and e-learning are in high demand all around the world, not only in Bangladesh.

AI may help with digitalization in a variety of ways, including digital relationship management, digital channel adoption, digital identity verification, digital onboarding, digital fraud protection, and more.

The Mujib Year is in full swing with the implementation of over 100 online citizen services.

Bangladesh, as well as the rest of the world, will now place a greater emphasis on digitizing government services. Bhutan, the Maldives, and Afghanistan, as well as Nigeria, Kenya, Rwanda, and Cameroon, are putting a greater emphasis. All of these factors have raised global demand, presenting a huge opportunity for Bangladesh's ICT industry to advance to the next level and become a prominent provider of ICT solutions.

Bangladesh should target both developed and developing countries while delivering modern technologies such as AI, Blockchain, Big Data, and IoT services. In the coming decade, Africa, as well as some nations in Southeast and Middle Asia, will be key markets for egovernance services. Bangladesh is adequately equipped to assist these nations.

\section{CONCLUSION AND POLICY RECOMMENDATIONS}

Bangladesh is a prospective industrial revolution country. Bangladesh will experience great economic growth over a period if Industry 4.0 can be implemented due to the country's large human resources and environmental support.

Using CPS, IoT, and IoS in conjunction with ERP, PLM, SCM, MES, SAP, and other software systems, Industry 4.0 will lead to digitization and enhancement of the production and manufacturing process as well as the supply chain, resulting in production flexibility and smartness. Industry 4.0 encourages the integration of big data, CPS IoT, and artificial intelligence (AI).

The importance of digital platforms in the economy is growing all the time. In this digital platform economy, which has risen to prominence as a result of the COVID-19 pandemic, business opportunities are also expanding. However, in the coming days, gaining consumer trust and confidence would be a big task for the digital platform economy in Bangladesh.

Even though a large number of mobile applications are being released, there are no policies in place to govern their monetization. Bangladeshi workers in the digital platform economy work because they want to, rather than because they have been properly trained by the educational system. As a result, they've barely scratched the surface of the digital platform economy's potential.

The enormous young population of Bangladesh may gain greatly from the digital platform economy if they were adequately trained and equipped with market-relevant skills. As a result, the government must move quickly and place a high priority on the digital platform economy in its policy agenda to avoid falling behind other nations during the 4th industrial revolution. 
By lowering transaction costs, assisting in the validation of supplier quality and trustworthiness, and matching suppliers with prospective international customers, digital platform firms enable actors to participate in the global value chain. In addition to facilitating collaboration and integration into global value chains, digital platforms use tools like customer ratings to eliminate information frictions and help businesses build a reputable reputation (World Bank, 2020).

Because of Bangladesh's expanding relevance in the digital platform industry, the following policies are advocated to help the sector grow:

- Individuals with market-relevant skills, particularly technical and English language abilities, are empowered to engage in and benefit from the digital platform economy through specialized training.

- Investigate new financial tools and models for assuring the long-term viability of Bangladesh's digital platforms.

- Create a 5-year national plan for the development of the digital platform economy.

- Develop a national standard for the use of data collected through digital platforms.

- Amend consumer protection legislation to include digital platforms in their scope.

- Encourage international investors to invest in digital platforms in Bangladesh.

- Bring the digital platform economy's businesses and workers into the tax net.

- Raising digital literacy among the general public.

- Allow new enterprises entering the digital platform economy to take advantage of tax breaks.

- Use tax incentives to encourage brick-and-mortar businesses to go digital.

To close the demand and supply gap between industry and academics and meet the industrial need, a tri-partite collaboration between industry, government, and academia should be formed. This will assist meet global and local demands, increase foreign reserves, and increase job prospects. A nation's destiny is determined by its visionaries. Prime Minister Sheikh Hasina has set the goal of transforming Bangladesh into a Digital Bangladesh. Bangladesh is on its path to becoming one of the world's leading ICT solution providers, thanks to her strong leadership and the combined efforts of the government and industry.

\section{AUTHOR CONTRIBUTIONS}

Conceptualization: Mohammed Masum Iqbal, Nurul Mohammad Zayed

Data Curation: Mohammed Masum Iqbal, Nurul Mohammad Zayed

Formal Analysis: Mohammed Masum Iqbal, Nurul Mohammad Zayed

Funding Acquisition: K. M. Anwarul Islam, Nurul Mohammad Zayed

Project Administration: Mohammed Masum Iqbal, Nurul Mohammad Zayed,

Software: Mohammed Masum Iqbal, Shahiduzzaman Khan Shahi, Tahrima Haque Beg

Validation: Mohammed Masum Iqbal, Tahrima Haque Beg, Nurul Mohammad Zayed

Writing - Original Draft: Mohammed Masum Iqbal, Nurul Mohammad Zayed

Writing - Review \& Editing: K. M. Anwarul Islam, Nurul Mohammad Zayed

\section{CONFLICT OF INTEREST STATEMENT}

The authors declare that they have no competing interests. 


\section{ACKNOWLEDGEMENT}

All authors contributed equally to the conception and design of the study

\section{REFERENCES}

Adhikari, R. (2020). Harnessing the Potential of the Fourth Industrial Revolution in South Asia. In Trade and Regional Integration in South Asia. Springer, Singapore, 295-319. Retrieved from https://link.springer.com/chapter/10.1007/978-981-15-3932-9_16

Arntz, M., Gregory, T., \& Zierahn, U. (2016). The risk of automation for jobs in OECD countries. Retrieved from https://www.oecd-ilibrary.org/social-issues-migrationhealth/the-risk-of-automation-for-jobs-in-OECD-countries_5jlz9h56dvq7-en

Bahrin, M.A.K., Othman, M.F., Azli, N.N., \& Talib, M.F. (2016). Industry 4.0: A review on industrial automation and robotics. Jurnal Teknologi, 78(6-13), 137-143. Retrieved from https://www.researchgate.net/publication/304614356_Industry_40_A_review_on_industr ial_automation_and_robotic

Berawi, M.A. (2018). Utilizing big data in industry 4.0: Managing competitive advantages and business ethics. International Journal of Technology, 3(1), 430-433. Retrieved from https://www.researchgate.net/publication/324831345_Utilizing_Big_Data_in_Industry_4 0_Managing_Competitive_Advantages_and_Business_Ethics

BoostDot. (2020). Current trends of digital marketing in Bangladesh. Retrieved from https://boostdot.net/digital-marketing-in-bangladesh/

Deloitte. (2018). The rise of the platform economy. Amsterdam: Deloitte. Retrieved from https://www2.deloitte.com/content/dam/Deloitte/nl/Documents/humancapital/deloittenlhc-reshaping-work-conference.pdf

Ezenwa, O., Stella, A., \& Agu, A.O. (2018). Effect of competitive intelligence on competitive advantage in inn son technical and industry limited, Enugu State, Nigeria. International Journal of Business, Economics \& Management, 1(1), 28-39. Retrieved from https://doi.org/10.31295/ijbem.v1n1.25

Fintech BD. (2019, May 22). Digital Economy for a Digital Bangladesh. Retrieved from http://www.fintechbd.com/digital-economy-for-a-digital-bangladesh/

Frey, C. B., \& Osborne, M. A. (2017). The future of employment: How susceptible are jobs to computerization? Technological forecasting and social change, 114, 254-280. Retrieved from https://www.sciencedirect.com/science/article/abs/pii/S0040162516302244

Ghobakhloo, M., \& Fathi, M. (2019). Corporate survival in Industry 4.0 era: the enabling role of learning digitized manufacturing. Journal of Manufacturing Technology Management. 
Retrieved from https://www.researchgate.net/publication/338204494_Industry_40_ Digitization_and_Opportunities_for_Sustainability

Gilchrist, A. (2016). Introducing Industry 4.0. Apress, Berkeley, $C A$. Retrieved from https://link.springer.com/chapter/10.1007/978-1-4842-2047-4_13

Hughes, T. P. (2004). A Century of Invention and Technological Enthusiasm. Retrieved from https://www.amazon.com/Thomas-Hughes-Invention-TechnologicalEnthusiasm/DP/B008VQVM66

Iyer, V. G. (2018). Strategic Environmental Assessment (SEA) Process for Sustainable Industrial Automation, Electrical, Mechanical, and Robotics Systems Sustainability Excellence Achievements. DEStech Transactions on Engineering and Technology Research.

Kim, N. (2018). Prospects of Least Developed Countries meeting the graduation criteria by 2030. UN CDP Policy Review, (8). Retrieved from https://papers.ssrn.com/sol3/papers.cfm?abstract_id=3299977

Macpherson, C. B. (1962). The Unfinished Revolution: An Essay on the Sources of Influence of Marxism and Communism. Retrieved from https://www.jstor.org/stable/2146334?seq=1\#metadata_info_tab_contents

Oxera. (2015). Benefits of Online Platforms. Oxford: Oxera. Retrieved from https://www.oxera.com/wp-content/uploads/2018/07/The-benefits-of-onlineplatformsmain-findings_October-2015.pdf.pdf

Park, S. C. (2018). The Fourth Industrial Revolution and implications for innovative cluster policies. AI \& SOCIETY, 33(3), 433-445. Retrieved from https://link.springer.com/article/10.1007/s00146-017-0777-5

Philbeck, T., \& Davis, N. (2018). The Fourth Industrial Revolution. Journal of International Affairs, 72(1), 17-22. Retrieved from https://www.jstor.org/stable/26588335?seq=1\#metadata_info_tab_contents

Rashid, M.H. (2020). Prospects of digital financial services in Bangladesh in the context of the fourth industrial revolution, Asian Journal of Social Science, 2(5), 88-95. Retrieved from https://doi.org/10.34104/ajssls.020.088095

Schwab, K. (2017). The fourth industrial revolution. Currency. Retrieved from https://www.penguinrandomhouse.com/books/551710/the-fourth-industrial-revolution -by-klaus-Schwab/ 
Smil, V. (2005). Creating the twentieth century: Technical innovations of 1867-1914 and their lasting impact. Oxford University Press. Retrieved from https://www.jstor.org/stable/40061298?seq=1\#metadata_info_tab_contents

Statista.com. (2020, October 24). Leading countries based on Facebook audience size as of October 2020. Retrieved from https://www.statista.com/statistics/268136/top_15countries-based-on-number-of-facebook-users/

Walcott, S. M. (2017). Chinese Science and Technology Industrial Parks. Routledge. https://doi.org/10.4324/9781315198170

World Economic Forum. (2020). Bend, don't break: how to thrive in the Fourth Industrial Revolution. https://www.weforuhttps//www.weforum.org/agenda/2020/01/the-fourth-industrialrevolution-is-changing

Zhong, R. Y., Xu, X., Klotz, E., \& Newman, S. T. (2017). Intelligent manufacturing in the context of industry 4.0: a review. Engineering, 3(5), 616-630. Retrieved from https://www.sciencedirect.com/science/article/pii/

Zhaltyrbayeva, R., Shalkharov, Y. S., Bitemirov, K. T., Ismailova, B. S., Kurmanova, A. K., Berdibaev, Y. M. \& Zayed, N. M. (2021). THE LEGAL STATUS OF THE DESIGNATION OF ARTIFICIAL INTELLIGENCE IN A SYSTEM OF MODERN LAW. Journal of Legal, Ethical and Regulatory Issues, 24(4), 1-8.

\section{Copyrights}

Copyright for this article is retained by the author(s), with first publication rights granted to the journal. This is an open-access article distributed under the terms and conditions of the Creative Commons Attribution license (https://creativecommons.org/licenses/by/4.0). 